\title{
Thermal Properties and Segregation Behavior of Pt Nanowires Modified with Au, Ag, and Pd Atoms: A Classical Molecular Dynamics Study
}

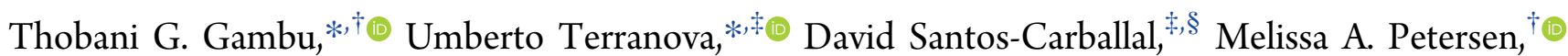
Glenn Jones, ${ }^{\|}$Eric van Steen, ${ }^{\dagger}$ and Nora H. de Leeuw ${ }^{*}, \neq, \perp \subset$

${ }^{\dagger}$ Catalysis Institute, Department of Chemical Engineering, University of Cape Town, Private Bag X3, Rondebosch 7701, South Africa

${ }^{\ddagger}$ School of Chemistry, Cardiff University, Main Building, Park Place, Cardiff CF10 3AT, United Kingdom

${ }^{\S}$ Materials Modelling Centre, School of Physical and Mineral Sciences, University of Limpopo, Private Bag X1106, Sovenga 0727, South Africa

"Johnson Matthey Technology Center, Blount's Court, Sonning Common, Reading RG4 9NH, United Kingdom

${ }^{\perp}$ Department of Earth Sciences, Utrecht University, Princetonplein 8A, Utrecht 3584 CD, Netherlands

\section{Supporting Information}

ABSTRACT: Platinum nanowires (NWs) have been reported to be catalytically active toward the oxygen reduction reaction (ORR). The edge modification of Pt NWs with metals $M(M=\mathrm{Au}, \mathrm{Ag}$, or Pd) may have a positive impact on the overall ORR activity by facilitating diffusion of adsorbed oxygen, $\mathrm{O}_{\mathrm{ads}}$, and hydroxyl groups, $\mathrm{OH}_{\mathrm{ads}}$, between the $\{001\}$ and $\{111\}$ terraces. In the present study, we have employed classical molecular dynamics simulations to investigate the segregation behavior of $\mathrm{Au}, \mathrm{Ag}$, and Pd decorating the edges of Pt NWs. We observe that, under vacuum conditions, Pd prefers to diffuse toward the core rather than stay on the NW surface. $\mathrm{Ag}$ and $\mathrm{Au}$ atoms are mobile at temperatures as low as $900 \mathrm{~K}$; they remain on the surface but do not appear to be preferentially more stable at edge sites. To effect segregation of $\mathrm{Au}$ and $\mathrm{Ag}$ atoms toward the edge, we propose annealing in the presence of different reactive gas environments. Overall, our study suggests potential experimental steps required for the synthesis of Pt nanowires and nanoparticles with improved $\mathrm{O}_{\text {ads }}$ and $\mathrm{OH}_{\text {ads }}$ interfacet diffusion rates and consequently an improved ORR activity.

\section{INTRODUCTION}

It has been argued that the slow kinetics of the oxygen reduction reaction (ORR) at the cathode-electrode of protonexchange membrane fuel cells (PEMFCs) causes over $67 \%$ of the drop in potential that is observed with increasing current density. ${ }^{1}$ Of all purely metallic catalysts, platinum is the most catalytically active metal for this reaction. ${ }^{2}$ However, due to its high cost, the amount of platinum in the fuel cell ought to be reduced but without affecting the catalytic activity and stability. As such, small nanoparticles (NPs) are currently utilized as catalysts for the ORR owing to their high surface area to mass/ volume ratios. ${ }^{1}$ However, the stability of these NPs is still a significant problem ${ }^{3}$ with degradation occurring via multiple mechanisms, including (1) direct and indirect dissolution of $\mathrm{Pt}$ and (2) agglomeration of the particles. ${ }^{1,3-5}$ Direct dissolution of Pt occurs at electrode potentials above $1.188 \mathrm{~V}$ (vs standard hydrogen electrode, SHE), while indirect dissolution occurs via $\mathrm{PtO}$ formation at electrode potentials above $0.980 \mathrm{~V}$ (vs SHE). Both dissolution processes result in the loss of the electro- chemically active surface area (ECSA). ${ }^{4}$ The dissolved $\mathrm{Pt}^{2+}$ cations may redeposit on the surface of larger Pt NPs, a process known as Ostwald ripening, or diffuse toward the cell membrane where they are reduced to electrically detached $\mathrm{Pt}$ NPs through hydrogen crossover. ${ }^{4}$ Consequently, this lowers the mass specific activity of the Pt-based system. Recently, oneand three-dimensional Pt nanowires (NWs) and NW networks ${ }^{6}$ have been shown to have not only better or comparable durability but also higher catalytic activities compared to small NPs. $^{7-10}$ These nanomaterials undergo minimal loss of the ECSA during accelerated degradation tests given their multiple anchoring sites on the carbon support and fewer undercoordinated atoms compared to small Pt NPs, thus making them ideal candidates for the ORR catalysts.

Received: March 22, 2019

Revised: July 21, 2019

Published: July 22, 2019 
Pt NPs are predominantly enclosed by $\{111\}$ and $\{001\}$ facets, as predicted by a Wulff construction based on surface free energies of different atomic arrangements. ${ }^{11-13}$ We further anticipate that these same facets will enclose Pt NWs. In fact, many wet-chemistry synthesis methods have suggested that $\mathrm{Pt}$ NWs grow along the [110] direction leading to $\{111\}$ and $\{001\}$ facets. $^{14-16}$

The ORR activity on the low-Miller index surfaces of Pt has been measured using rotating disc electrode experiments. ${ }^{17-19}$ In nonadsorbing electrolytes, the $\mathrm{Pt}(111)$ facet is the most ORR active low-Miller index Pt surface. ${ }^{17-19}$ Theoretical studies have also predicted that, under nonadsorbing electrolytes, the ORR activity is higher on $\mathrm{Pt}(111)$ than on the (001) surface. $^{20-23}$ This difference has been attributed to poisoning by the strong adsorption of oxygen-containing species (OCS*), particularly $\mathrm{OH}_{\mathrm{ads}}$, which is more severe on $\mathrm{Pt}(001)$ than on (111) surfaces. ${ }^{17,23-26}$ Calculated reaction and activation energies for the ORR mechanism further indicate that on $\mathrm{Pt}(111)$ and (001) the rate limiting step is the hydrogenation of $\mathrm{O}_{\mathrm{ads}}$ and $\mathrm{OH}_{\mathrm{ads}}$, respectively. ${ }^{2,23}$ It has generally been assumed that different terraces of multifaceted nanomaterials, specifically NPs, behave independently, owing to the strong binding of OCS* at these edge sites. ${ }^{20,27}$ We have recently shown that high coverage of atomic oxygen $\left(\mathrm{O}_{\mathrm{ads}}\right)$ at the edge sites of nanorods significantly reduces the interfacet diffusion barriers of $\mathrm{O}_{\mathrm{ads}}$ over the edges. ${ }^{28}$ However, the diffusion of $\mathrm{OH}_{\mathrm{ads}}$ over the edge of a pure $\mathrm{Pt}$ nanorod is unlikely to be improved by increasing its coverage at edge sites due to attractive $\mathrm{OH}-\mathrm{OH}$ lateral interactions that result from hydrogen bonding. Increasing the rate of interfacet species exchange may provide an alternative and efficient ORR pathway where $\mathrm{O}_{a d s}$ and $\mathrm{OH}_{\mathrm{ads}}$ hydrogenation steps are no longer rate-limiting. Experimentally, Komanicky et al. ${ }^{29,30}$ have reported that, in nanofaceted $\mathrm{Pt}$ surfaces composed of alternating $\{111\}$ and $\{100\}$ facets, the ORR activity is much higher than that if we merely average the activities of singlecrystal surfaces under the same conditions. It has been suggested that this could be a result of cooperative catalysis involving diffusion of adsorbed $\mathrm{O}_{2}$ and $\mathrm{OH}$ species between the $\{111\}$ and $\{100\}$ facets. This cooperative catalysis may be limited by the rate of exchange of interfacet species, which in turn may be predetermined by the reactivity of edge sites toward ORR intermediates.

The adsorption of $\mathrm{OCS}^{*}$ is much weaker on $\mathrm{Au}, \mathrm{Ag}$, and $\mathrm{Pd}$ surfaces than on Pt surfaces. ${ }^{20}$ Therefore, Pt NPs and NWs whose edges are decorated with $M(M=\mathrm{Au}, \mathrm{Ag}$, or $\mathrm{Pd})$ atoms may have reduced diffusion barriers of $\mathrm{OCS}^{*}$ between the $\{001\}$ and $\{111\}$ facets. However, it is still not clear whether such structures can be synthesized, since their stability is unknown. $\mathrm{Au}, \mathrm{Ag}$, and $\mathrm{Pd}$ have lower surface energies compared to Pt. ${ }^{31}$ In line with the Wulff construction theorem, ${ }^{32}$ we anticipate that equilibrium nanowires/nanoparticles will have these modifiers ( $\mathrm{Au}, \mathrm{Ag}$, and $\mathrm{Pd}$ ) at the surface. Moreover, given their large equilibrium lattice parameters, ${ }^{33}$ subsurface $\mathrm{Au} / \mathrm{Ag}$ atoms may result in lattice strain, which might also contribute to the surface segregation driving force for these atoms in $\mathrm{Pt}$, particularly at low concentrations, unless the $\mathrm{Pt}-\mathrm{Au}$ or $\mathrm{Pt}-\mathrm{Ag}$ interaction energy is larger than that of $\mathrm{Pt}-\mathrm{Pt}^{34}$

The thermal and segregation properties of monometallic and bimetallic nanomaterials have been studied quite extensively using empirical force field potential methods. ${ }^{35-41}$ In particular, the melting and segregation behavior of PtAu systems has been studied using classical force fields. ${ }^{38,42}$ Yang et $\mathrm{al}^{38}$ reported on the melting behavior of core-shell icosahedral NPs containing 561 atoms. Their molecular dynamics (MD) simulations showed that $\mathrm{Au}$ atoms remain predominantly in the shell region even near the melting transition. Using modified analytic embedded method potentials and a Metropolis Monte Carlo method, Deng et al. ${ }^{42}$ investigated the segregation behavior of PtAu NPs with various Au concentrations. They observed a competitive site segregation behavior with the following preferential order for $\mathrm{Au}$ atoms: vertices $>$ edges $>\{001\}$ facets $>\{111\}$ facets $>$ second subsurface layer, which meant that increasing $\mathrm{Au}$ concentration resulted in an onion-like structure. ${ }^{42}$

Cheng and $\mathrm{Hou}^{43}$ and De Clercq et al. ${ }^{44}$ reported that PtPd NWs and NPs segregate to form Pd-enriched surface and second subsurface layers. In both studies, it was observed that site occupation preference followed an order similar to that observed for the PtAu NPs. These theoretical studies appear to be in agreement with experimental measurements of Watson and Attard $^{45}$ who found, using a combination of Auger electron spectroscopy and low-energy electron diffraction techniques, that Pd segregates toward the surface of PtPd single-crystal alloys. However, it has recently been reported that galvanic displacement of an adsorbed copper layer on $\mathrm{Pd}_{9} \mathrm{Au}$ ultrathin NWs with $\mathrm{Pt}^{2+}$ cations resulted in $\mathrm{Pd} \mathrm{NWs}$ with $\mathrm{Au}$ edges and $\mathrm{Pt}$ terraces. ${ }^{46}$ The segregation behavior of $\mathrm{Pd}$ relative to $\mathrm{Pt}$ here seems to be in contrast to what is predicted by former studies. ${ }^{43,44}$ A classical MD study by Sankaranarayanan et al. ${ }^{35}$ concluded that melting in PtPd nanoclusters is preceded by the diffusion of Pd atoms toward the core of the cluster and $\mathrm{Pt}$ atoms toward the surface, in agreement with the latter experimental study. Using density functional theory (DFT), Ruban et al. ${ }^{47}$ reported no segregation and moderate antisegregation behavior for a $\mathrm{Pt}(111)$ host slab with $\mathrm{Pd}$ impurities and a $\mathrm{Pd}(111)$ host slab with Pt impurities, respectively. In a more recent DFT study, Tripkovic et al. ${ }^{48}$ reported that, in PtPd binary systems, both cases where Pd is a host and solute element, there is no pronounced driving force for $\mathrm{Pd}$ surface segregation irrespective of the surface oxidation state. We therefore anticipate that, unlike in PtAu and PtAg systems, the PtPd system will exhibit a much lower propensity to segregate.

In summary, the effects of interfacet exchange of $\mathrm{O}_{\text {ads }}$ and $\mathrm{OH}_{\mathrm{ads}}$ on the overall ORR activity of $\mathrm{Pt} \mathrm{NWs}$ can be investigated by controlling the adsorption strength of ORR intermediates at edge sites. Due to the weak interaction of $\mathrm{O}_{\text {ads }}$ and $\mathrm{OH}_{\text {ads }}$ with $\mathrm{Au}, \mathrm{Ag}$, and Pd surfaces, ${ }^{20}$ successful synthesis of $\mathrm{Pt} \mathrm{NWs}$ with $\mathrm{Au}, \mathrm{Ag}$, or $\mathrm{Pd}$ edges will enable a direct investigation of the effect of species exchange on the overall ORR activity. While no direct method for synthesizing edgedecorated Pt NWs has been reported, the current literature suggests that electroless replacement of a $\mathrm{Cu}$ monolayer in a stoichiometric solution of $\mathrm{Pt}^{2+}$ and $\mathrm{Ir}^{3+}$ results in a randomly mixed $\mathrm{Pt}_{1-x} \mathrm{Ir}_{x}$ surface layer. ${ }^{49}$ If this behavior holds for other cases when Ir is replaced by $\mathrm{Au}, \mathrm{Ag}$, or $\mathrm{Pd}$, it is of interest to understand if such structures can segregate to edge-decorated Pt NWs. In this study, we have used classical MD simulations to investigate the stability of $\mathrm{Au}, \mathrm{Ag}$, and $\mathrm{Pd}$ edge-decorated $\mathrm{Pt}$ NWs under different thermal conditions; this ought to give an indication of whether thermal annealing can be used in the synthesis of these edge-decorated Pt NWs when starting from a mixed shell structure. 


\section{COMPUTATIONAL METHODOLOGY}

Classical MD simulations were conducted to study the thermal stability of pure hexagonal Pt NWs and their modifications with $\mathrm{Au}, \mathrm{Ag}$, and $\mathrm{Pd}$ atoms. These simulations were carried out using DL_POLY Classic. ${ }^{50}$ We performed a canonical ensemble (NVT) sampling with the "Gaussian constraints" Evans thermostat. ${ }^{51}$ In all our simulations, the velocity Verlet integration algorithm was used to integrate the equations of motion with an integration time step of 2 fs. We ran the simulations for $4 \mathrm{~ns}$ to ensure a sufficient time for equilibration of the segregation behavior. The system's total energy generally reached equilibration within 10 ps (for further details, see the Supporting Information, Figures S1 and S2).

A cutoff radius of $7.5 \AA$, equivalent to 2.7 times the nearestneighbor distance of bulk $\mathrm{Pt}$, was used with an Ewald precision of $1 \times 10^{-5}$. The interatomic interactions between two atoms were described using the Sutton-Chen ${ }^{52}$ many-body potential and the total energy of a typical system $\left(U_{\text {total }}\right)$ is given by

$$
\begin{aligned}
& U_{\text {total }}=\sum_{i} \epsilon\left[\frac{1}{2} \sum_{j \neq i}\left(\frac{a}{r_{i j}}\right)^{n}-c \sqrt{\rho_{i}}\right] \\
& \rho_{i}=\sum_{j \neq i}\left(\frac{a}{r_{i j}}\right)^{m}
\end{aligned}
$$

The energy parameter is represented by $\epsilon$, while $a$ and $r_{i j}$ are the lattice parameter and distance between atoms $i$ and $j$, respectively. $n$ and $m$ are integer parameters chosen such that $n$ is always greater than $m ; c$ is a dimensionless scaling parameter. In this work, we described homonuclear interactions using the original Sutton-Chen potential parameters as reported by Kimura et al. $^{53}$ (see Table 1 ).

\section{Table 1. Sutton-Chen Potential Parameters ${ }^{52}$}

\begin{tabular}{cccccc} 
interactions & $\epsilon(\mathrm{meV})$ & $a(\AA)$ & $n$ & $m$ & $c$ \\
$\mathrm{Pt}-\mathrm{Pt}$ & 19.768 & 3.920 & 10 & 8 & 34.428 \\
$\mathrm{Au}-\mathrm{Au}$ & 12.896 & 4.080 & 10 & 8 & 34.428 \\
$\mathrm{Ag}-\mathrm{Ag}$ & 2.533 & 4.090 & 12 & 6 & 145.658 \\
$\mathrm{Pd}-\mathrm{Pd}$ & 4.126 & 3.890 & 12 & 7 & 108.526 \\
\hline
\end{tabular}

These parameters were optimized by fitting to various experimental data and to reproduce, in good agreement, the experimental cohesive energy, elastic constants, and phonon modes for all bulk elements investigated in this paper. ${ }^{53,54}$ For heteronuclear interactions, we used the standard mixing rules, ${ }^{41}$ that is, an arithmetic mean for $m^{\mathrm{AB}}$ and $n^{\mathrm{AB}}$ and a geometric mean for $a^{\mathrm{AB}}, \epsilon^{\mathrm{AB}}$, and $c^{\mathrm{AB}}$.

To identify the phase transition region for each of our NW models, we make use of the Steinhardt bond order parameters, ${ }^{55}$ more specifically the $Q_{6}$ parameter. The $Q_{6}$ bond order parameter gives a quantitative measure of bond symmetry, taking unique and nonzero values of $0.575,0.485$, and 0.511 for the face-centered cubic (fcc), hexagonal closepacked (hcp), and body-centered cubic (bcc) structures, respectively, while it equates to zero for liquid and amorphous structures. ${ }^{36,56}$ A large change of the $Q_{6}$ parameter within a short temperature range indicates a phase transition, as seen in Figure 1. A detailed description of the calculation of bond order parameters is presented elsewhere. ${ }^{56}$

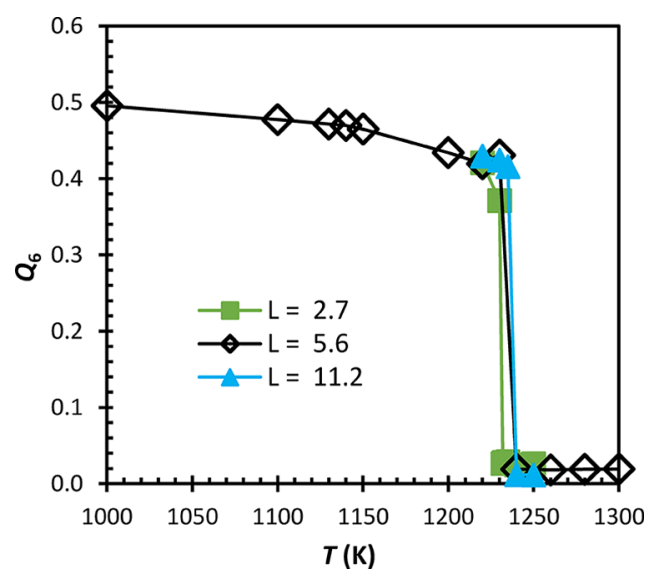

Figure 1. Bond order parameter $\left(Q_{6}\right)$ as a function of temperature (T) for Pt NW models with a diameter of $\sim 4 \mathrm{~nm}$; L represents periodic axial length in $\mathrm{nm}$.

As a starting point, we investigate the melting properties of Pt NWs of various lengths. Figure 1 shows a negligible variation in the melting point as a function of axial length for a $4 \mathrm{~nm}$ diameter NW. The remainder of our study therefore focuses on a single-size NW with a periodic axial length of 5.6 $\mathrm{nm}$. In all our simulations, we ensure that the shortest distance between periodic NWs is much larger than $7.5 \AA$, the cutoff radius for pair interactions.

To generate bond order parameter plots for each NW system, we ran MD simulations at different temperatures between 300 and $1300 \mathrm{~K}$. To improve the resolution of the melting point, we used $10 \mathrm{~K}$ temperature increments near the phase transition region and wider ranges everywhere else. We averaged properties over the last 2 ns of each MD simulation and made use of the radial distribution function, $g(r)$, to study the average number of neighboring $X-Y$ atomic pairs. The latter is particularly useful in identifying whether segregation has resulted in island formation or homogeneous mixing.

\section{RESULTS AND DISCUSSION}

3.1. Melting Properties of Pt NWs. Several studies have investigated the melting behavior of different pure and bimetallic NPs of various sizes. ${ }^{35,38,43,57-60}$ Generally, the melting point temperature increases with increasing NP size. In our present study, we have investigated the melting behavior of differently sized Pt NWs (see Figure 2).

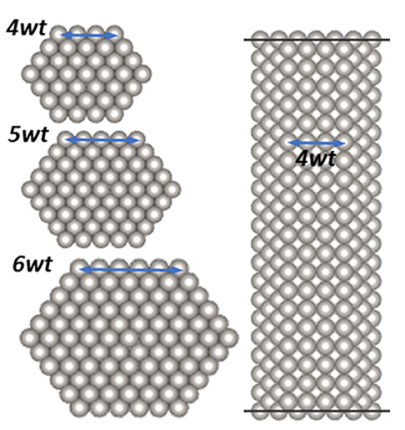

Figure 2. Model Pt NWs with various diameters. Xwt nanowire consists of $X$ atomic rows along each of the size facets. Each NW consists of two $\{001\}$ and four $\{111\}$ facets. All NW models have a periodic length of $5.6 \mathrm{~nm}$ equivalent to 20 atoms along the NW axis within one periodic cell. 
Since crystallite symmetry changes through phase transitions from fcc to hcp and then to a liquid/amorphous-like state, we can use the $Q_{6}$ bond order parameter to study phase transitions. In Figure 3, we present the $Q_{6}$ parameter as a

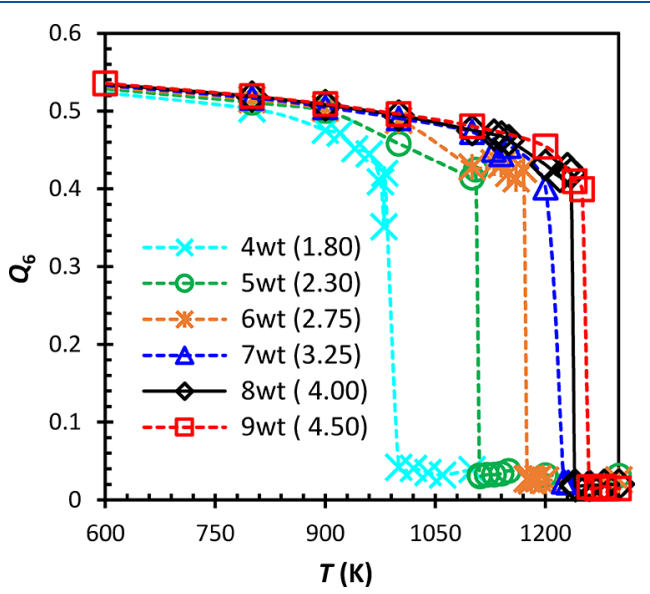

Figure 3. Bond order parameter $\left(Q_{6}\right)$ as a function of temperature (T) for differently sized Pt NWs models. Values within brackets represent diameters in $\mathrm{nm}$.

function of temperature for various NW diameters. $Q_{6}$ undergoes a sharp decrease at a different temperature for each NWs, indicating a phase transition from an fcc-like crystallite symmetry to an amorphous-like structure. This prediction of the size-dependent melting point is in good agreement with previous studies, which have reported a strong correlation between these two parameters. ${ }^{61-63}$

Extrapolating a linear plot of melting temperature versus the inverse of the NP diameter $\left(d^{-1}\right)$ to the $y$-intercept allows a first estimate of the bulk melting temperature. ${ }^{62,63}$ In our present study, the predicted bulk melting temperature $\left(T_{\mathrm{m}}\right)$ of $1458 \mathrm{~K}$ for $\mathrm{Pt}$, shown in Figure 4 , is lower than the

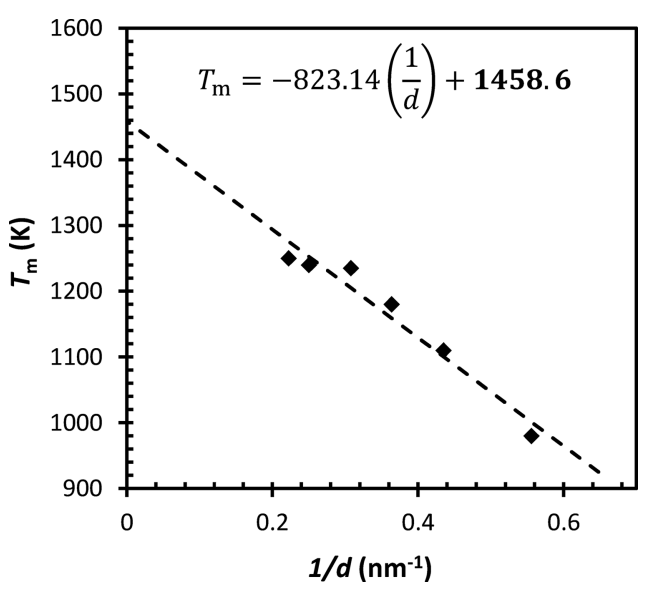

Figure 4. Correlation of $\mathrm{Pt} \mathrm{NW}$ melting point temperature $\left(T_{\mathrm{m}}\right)$ to the inverse of NW diameter $(1 / d)$.

experimental value of $2041 \mathrm{~K}^{35}$ However, our predicted bulk melting temperature is in good agreement with an earlier theoretical study based on similar modeling parameters. ${ }^{64}$ This underprediction of $T_{\mathrm{m}}$ is possibly due to fitting of the SuttonChen parameters using a slightly larger lattice volume instead of the experimentally determined lattice. The quantumcorrected Sutton-Chen (Q-SC) potentials generated by fitting to experimental cohesive energies and lattice parameters at $0 \mathrm{~K}$ and considering zero-point effects ${ }^{53}$ have been used ${ }^{35-37,41}$ to predict more accurately the melting temperatures of bulk metals $^{35}$ compared with the original Sutton-Chen potentials used here. However, Q-SC potentials provide a poor prediction of the segregation behavior of $\mathrm{PtAu}$ and $\mathrm{PtAg}$ systems (see Figures S10 and S11). Instead, Figures S10 and S11 show that SC potentials agree with density functional theory calculations of atomic diffusion in the NW and hence, albeit less accurate at predicting the melting temperature of bulk $\mathrm{Pt}$, they represent a better choice in the context of this work.

3.2. Melting Properties of Modified Pt NWs. Here, we are interested in understanding how surface modification of $\mathrm{Pt}$ NWs with $M(M=\mathrm{Au}, \mathrm{Ag}$, and $\mathrm{Pd})$ affects their melting point temperature. For consistency, we use a constant NW size (8wt model) and only substitute the edge and outermost atomic shell atoms for edge modification and shell modification, respectively, as shown in Figure 5.
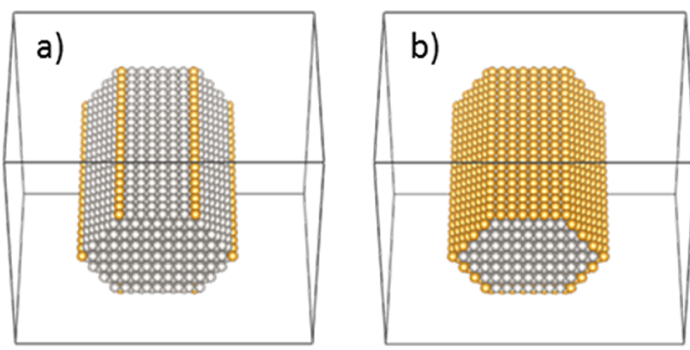

Figure 5. Illustration of (a) edge- and (b) shell-modified hexagonal Pt NWs (8wt).

Figure 6 presents the bond order parameter, $Q_{6}$, as a function of temperature for edge-modified $\mathrm{Pt}$ NWs. The

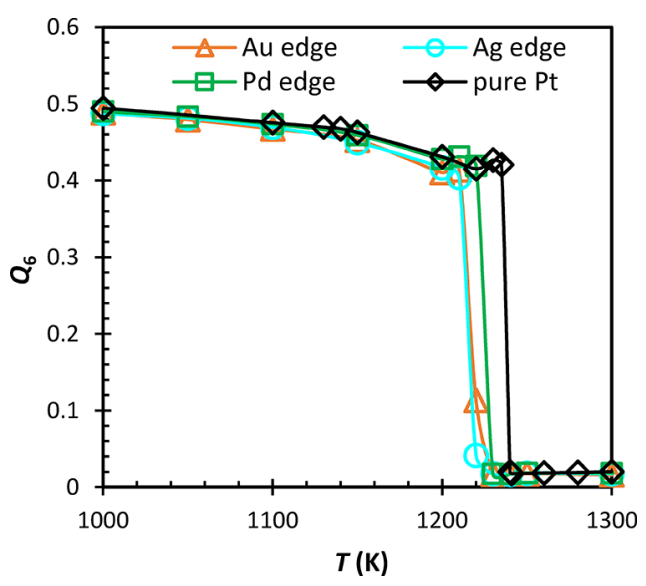

Figure 6. Bond order parameter $\left(Q_{6}\right)$ as a function of temperature $(T)$ for the $8 \mathrm{wt}(\sim 4 \mathrm{~nm}) \mathrm{Pt}$ NW model with $M(M=\mathrm{Au}, \mathrm{Ag}$, and $\mathrm{Pd})$ edge modifications.

modification of the edge with palladium lowers the melting point by ca. $10 \mathrm{~K}$ with respect to a purely platinum NW of the same diameter. The $\mathrm{Au}$ - and $\mathrm{Ag}$-modified $\mathrm{Pt} \mathrm{NWs}$ display a melting temperature of $1220 \mathrm{~K}$, which lies ca. $20 \mathrm{~K}$ below that of the pure-Pt NW.

The effects of full shell modification on the melting temperature are much larger, see Figure 7. $\mathrm{Au}, \mathrm{Ag}$, and $\mathrm{Pd}$ lower the melting point of the Pt NW by 120,80 , and $60 \mathrm{~K}$, 


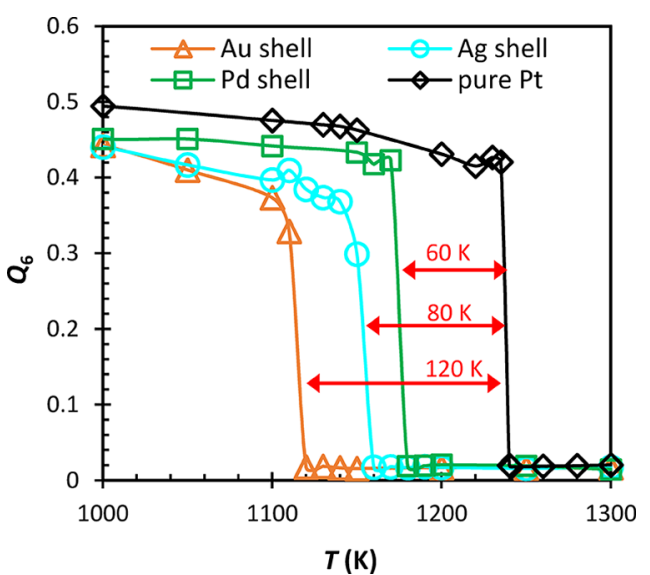

Figure 7. Bond order parameter $\left(Q_{6}\right)$ as a function of temperature $(T)$ for the $8 \mathrm{wt}(\sim 4 \mathrm{~nm}) \mathrm{Pt}$ NW model with $M(M=\mathrm{Au}, \mathrm{Ag}$, and $\mathrm{Pd})$ shell modifications.

respectively. This softening behavior is consistent with the different melting temperatures of $1337 \mathrm{~K}$ for bulk $\mathrm{Au}, 1235 \mathrm{~K}$ for $\mathrm{Ag}$, and $1828 \mathrm{~K}$ for $\mathrm{Pd}$, relative to $2041 \mathrm{~K}$ for bulk Pt. However, our results show that Au softens the Pt NW by $40 \mathrm{~K}$ compared to $\mathrm{Ag}$, despite the lower bulk melting point of $\mathrm{Ag}$ compared to Au. This might be due to the thin nature of the $\mathrm{Au}$ and Ag shells, which need to match the lattice constant of the underlying Pt NW lattice. With increasing Au and Ag shell thickness, this behavior will most probably reverse to match the bulk melting trends. Given the large discrepancy between the experimental melting temperature of bulk $\mathrm{Pt}$ and that predicted by the SC potentials, these small variations in the melting point as functions of the modifying element seem subtle. However, we believe that the observed trends have implications for the chemistry. What is of interest to experimental researchers is the prediction of an annealing temperature where $\mathrm{Au}, \mathrm{Ag}$, and $\mathrm{Pd}$ atoms would be mobile enough to segregate toward desired sites. Our results indicate that we may expect the lower bound of this temperature to vary with the type and quantity of the modifier, although the absolute magnitude remains undetermined.

A closer look at Figure S3 shows an initial decrease in the total energy of a Pd shell-modified Pt NW. Cheng and Hou ${ }^{43}$ attributed a similar behavior to a phase transformation. They argued that, at temperatures near the melting transition, the pentagon multishell-type structure transforms to the more energetically stable fcc structure. In our case, we attribute this decrease in total energy to favorable mixing/migration of $\mathrm{Pd}$ atoms toward the subsurface layers. As seen in Figure S12, this segregation behavior contradicts the DFT prediction.

In summary, the segregation behavior of the PtAu and PtAg systems, predicted by the methods applied here, is supported by DFT calculations; however, the PtPd segregation behavior is not. We would also like to point out further that the predicted temperatures of the onset of, for example, deformation and segregation may be underestimated as it is with the melting point of bulk Pt. Therefore, we emphasize that our results have quantitative limitations, as highlighted above. In particular, reported onset temperatures for deformation and segregation phenomena must be considered as underestimates. Despite these limitations, our classical MD approach provides significant qualitative insights, which are not accessible with routine $\mathrm{ab}$ initio methods, into the segregation of modified Pt NWs under vacuum conditions and provides a useful comparison between the behavior of different dopants.

3.3. Thermally Induced Segregation in Modified Pt NWs. 3.3.1. Constrained Segregation Behavior of $\mathrm{Ag}, \mathrm{Au}$, and $P d$. We further investigated the segregation behavior of $M$ atoms in the absence of structural relaxation by making use of hexagonal NW models with a periodic lattice length of ca. 2.2 $\mathrm{nm}$, a diameter of ca. $4.0 \mathrm{~nm}$ (1352 atoms), and following the procedure below:

(i) Define an atomic system $\left(\mathrm{S}_{0}\right)$ consisting of a mixture of at least two atomic types; in the present study, we consider PtM NW systems. Knowing the composition of $M$ in the Pt NW with bulk optimized Pt-Pt distances,

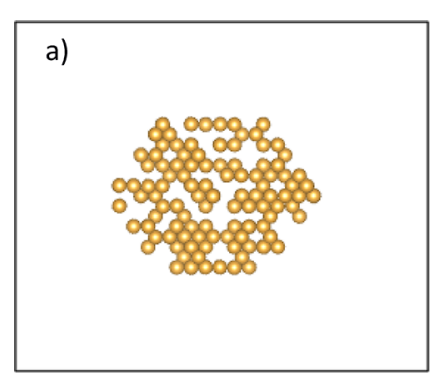

c)

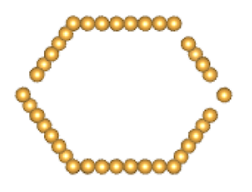

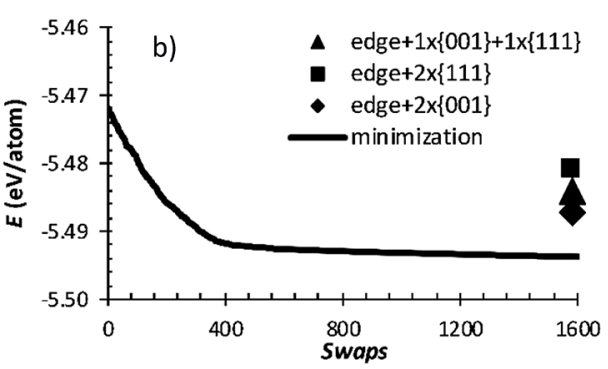

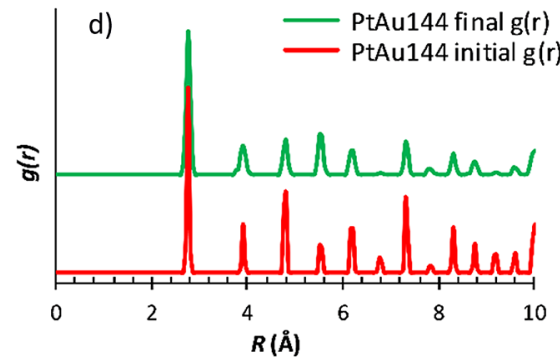

Figure 8. Evolution of ca. 10 atom \% Au-modified Pt NW under the energy minimization algorithm detailed in Subsection 3.3.1. (a) Initial and (c) final structures with Pt atoms hidden. Panel (b) shows the decrease in total energy (E) with the number of successful atomic swaps (Swaps), while panel (d) shows the radial $\mathrm{Au}-\mathrm{Au}$ pair distribution functions $(g(r))$ for the initial and final structures. 

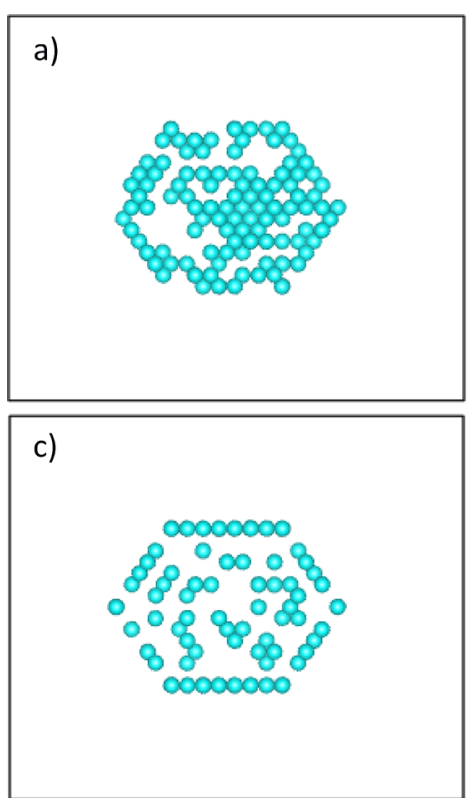
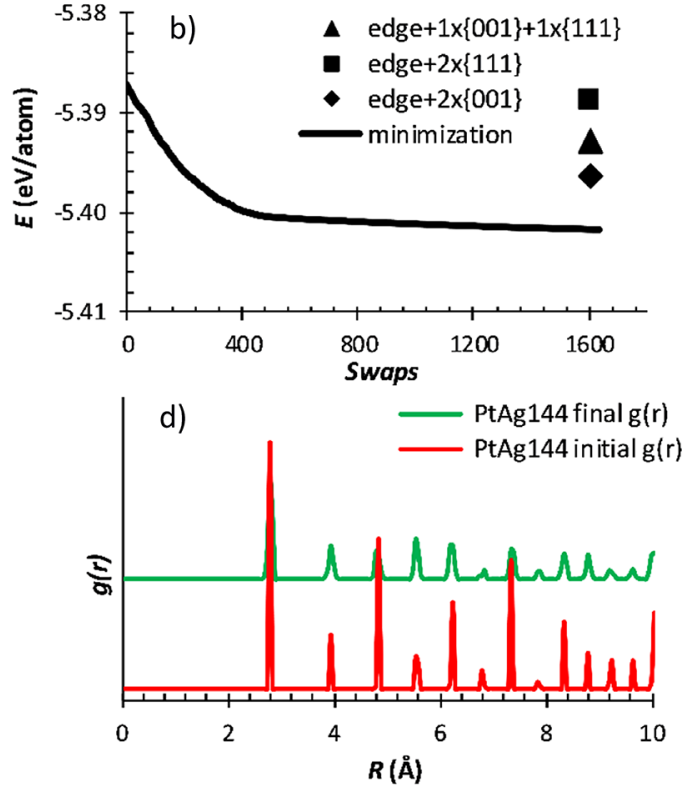

Figure 9. Evolution of ca. 10 atom \% Ag-modified Pt NW under the energy minimization algorithm detailed in Subsection 3.3.1. (a) Initial and (c) final structures with Pt atoms hidden. Panel (b) shows the decrease in total energy (E) with the number of successful atomic swaps (Swaps), while panel (d) shows the radial $\mathrm{Ag}-\mathrm{Ag}$ pair distribution functions $(g(r))$ for the initial and final structures.
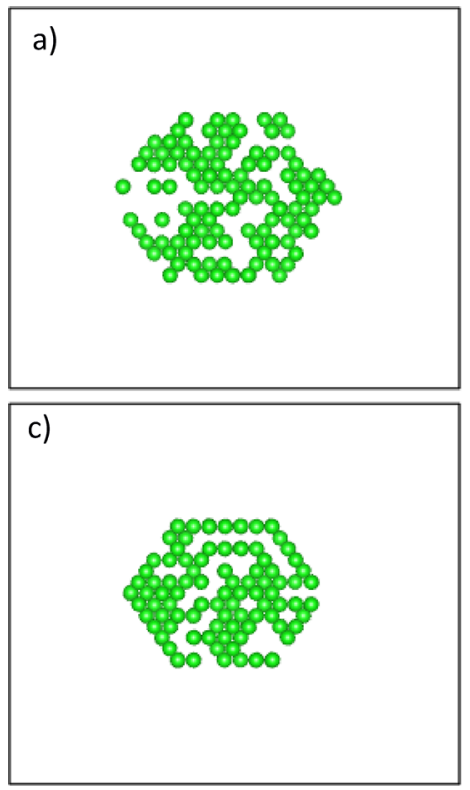
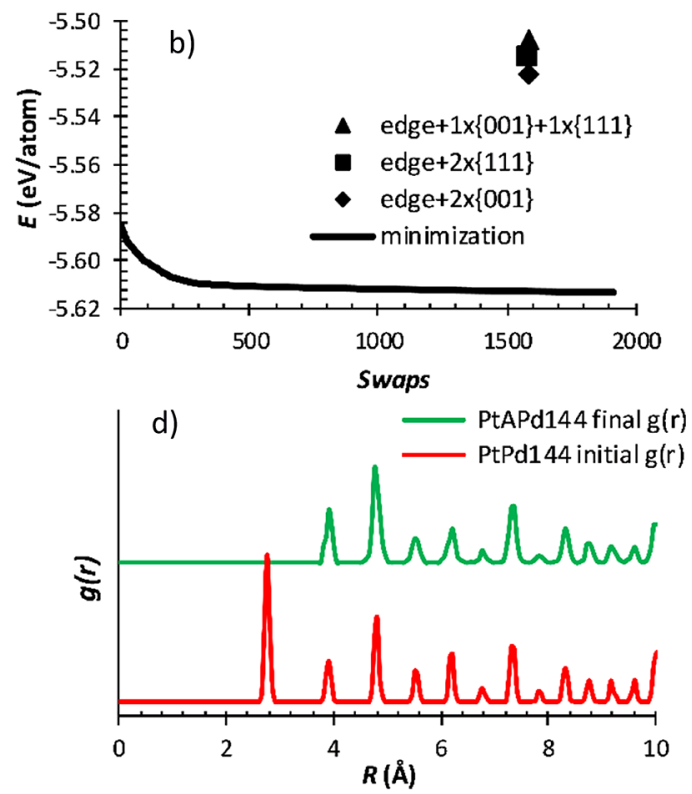

Figure 10. Evolution of ca. 10 atom \% Pd-modified Pt NW under the energy minimization algorithm detailed in Subsection 3.3.1. (a) Initial and (c) final structures with Pt atoms hidden. Panel (b) shows the decrease in total energy $(E)$ with the number of successful atomic swaps (Swaps), while panel $(\mathrm{d})$ shows the radial Pd-Pd pair distribution functions $(g(r))$ for the initial and final structures.

we randomly distributed $\mathrm{Pt}$ and $M$ atoms in the NW to generate $S_{0}$.

(ii) Calculate the energy of $S_{0}$ as $E_{0}$.

(iii) Randomly swap positions of two unique atomic types in $S_{0}$ to form a variation $S_{1}$.

(iv) Calculate the energy of $S_{1}$ as $E_{1}$.

(v) If $E_{1}<E_{0}$, rename $S_{1}$ to $S_{0}$, collect $E_{1}$, and set $E_{0}=E_{1}$; else if $E_{1} \geq E_{0}$, do nothing.

(vi) Repeat (ii)-(v) until a sufficient number of trial swaps has been attempted.

We present the results for systems with $144 \mathrm{M}$ atoms, enough to cover all edge and $\{001\}$ terrace sites. The minimization procedure is executed for $10^{6}$ trial swaps and a minimum of 1626 successful/accepted swaps for each PtM system covering over 6900 trial swaps per $M$ atom. Furthermore, we compare the energy minimization to that of perfectly segregated structures, that is, structures with $M$ atoms occupying (1) the edge and two $\{001\}$ terrace sites, (2) the edge and two $\{111\}$ terrace sites, and (3) the edge and one $\{001\}$ and one $\{111\}$ terrace site. Figures $8-10$ present the energy minimization results for all studied systems, including the $S_{0}$ and energy minimized structures, shown in panels a and c with Pt atoms hidden for clarity. More projections of these 
Table 2. Summary of $\mathrm{CN}_{M-M}$ and $\mathrm{CN}_{M-\mathrm{Pt}}$ Calculated from $g(r)$ Functions at Different Temperatures $(T)^{a}$

\begin{tabular}{|c|c|c|c|c|c|c|c|c|c|}
\hline \multirow[b]{2}{*}{$T(\mathrm{~K})$} & \multicolumn{3}{|c|}{ PtAu NW } & \multicolumn{3}{|c|}{ PtAg NW } & \multicolumn{3}{|c|}{ PtPd NW } \\
\hline & $\mathrm{CN}_{\mathrm{Au}-\mathrm{Au}}$ & $\mathrm{CN}_{\mathrm{Au}-\mathrm{Pt}}$ & $\mathrm{CN}_{0}$ & $\mathrm{CN}_{\mathrm{Ag}-\mathrm{Ag}}$ & $\mathrm{CN}_{\mathrm{Ag}-\mathrm{Pt}}$ & $\mathrm{CN}_{0}$ & $\mathrm{CN}_{\mathrm{Pd}-\mathrm{Pd}}$ & $\mathrm{CN}_{\mathrm{Pd}-\mathrm{Pt}}$ & $\mathrm{CN}_{0}$ \\
\hline 300 & 2.0 & 5.0 & 7.0 & 2.0 & 5.0 & 7.0 & 2.0 & 5.0 & 7.0 \\
\hline 1000 & 0.7 & 7.5 & 8.2 & 0.8 & 7.0 & 7.8 & 0.6 & 8.6 & 9.2 \\
\hline 1210 & 0.4 & 8.3 & 8.7 & 0.5 & 7.9 & 8.4 & $0.2^{*}$ & $11.0^{*}$ & $11.2^{*}$ \\
\hline 1220 & 0.4 & 8.4 & 8.8 & 0.4 & 8.9 & 9.3 & $0.1 * *$ & $11.2^{* * *}$ & $11.3 * *$ \\
\hline
\end{tabular}

$a^{*}$ ) for the PtPd system, $T=1220 \mathrm{~K}$, and $(* *)$ for the PtPd system, $T=1230 \mathrm{~K}$. Detailed $g(r)$ and integrated $g(r)$ plots for all three edge-modified systems are presented in Figures S7-S9.

model NWs are presented in Figures S4-S6 in the Supporting Information.

We observe that, in all cases, the energy-minimized structures are energetically preferred to the perfectly segregated structures. For the PtAu and PtAg NW systems, the total energy decreases with each atomic swap that results in surfaces of $\mathrm{Au}$ and $\mathrm{Ag}$, respectively (see Figures $8 \mathrm{~b}$ and $9 \mathrm{~b}$ ). This behavior is particularly strong for the PtAu system. The difference between the initial and final radial $\mathrm{Au}-\mathrm{Au}$ pair distribution function plot for the PtAu system is negligible (Figure 8d). In addition to the tendency of $\mathrm{Au}$ and $\mathrm{Ag}$ atoms to migrate to the surface, an almost full occupation of edge sites is observed over both $\{001\}-\{111\}$ and $\{111\}-\{111\}$ edges. While the final PtAu system has all $\mathrm{Au}$ atoms on the surface layer, edges fully covered and $\{111\}$ and $\{001\}$ partially covered, in the final PtAg structure, some Ag atoms are still occupying core sites from the second subsurface layer toward the core; see Figure 9c.

In contrast to the PtAu and PtAg systems, the PtPd system shows a decrease in total energy with every atomic swap resulting in subsurface/bulk Pd atoms (Figure 10 and Figure S6). Moreover, at this Pd concentration, we observe an almost homogeneous mixing of $\mathrm{Pt}-\mathrm{Pd}$ and a pure $\mathrm{Pt}$ atomic shell (Figure S6). From the radial $\mathrm{Pd}-\mathrm{Pd}$ pair distribution function plot of the final structure, we note that the first $\mathrm{Pd}$ coordination shell no longer contains any Pd atoms despite a high Pd-Pd coordination in the initial structure (Figure 10d).

3.3.2. Segregation Behavior in Edge-Modified PtM NWs. This subsection presents a further analysis of PtM structures resulting from the simulations discussed in Subsection 3.2. Based on coordination number $(\mathrm{CN})$ parameters derived from statistically averaged radial pair distribution functions, different types of segregation behavior are discussed. For example, if there is an overall migration of $M$ atoms from edge sites toward terrace sites, a significant decrease in the $M-M \mathrm{CN}\left(\mathrm{CN}_{M-M}=\right.$ $2)$ and increase in the $M-\mathrm{Pt} C N\left(\mathrm{CN}_{M-\mathrm{Pt}}=5\right)$ are expected. Moreover, an overall $M$ atom $\mathrm{CN}$, that is, $\mathrm{CN}_{0}=\mathrm{CN}_{M-M}+$ $\mathrm{CN}_{M-\mathrm{Pt}}$ larger than 9 indicates that $M$ atoms migrate toward subsurface layers. We should note that the total coordination number of any atom placed at the $\{001\}$ surface, $\{111\}$ surface, and in the bulk are 8,9 , and 12 respectively.

Our analysis, shown in Table 2, reveals that, with increasing temperature, the $\mathrm{Au}-\mathrm{Au} \mathrm{CN}$ decreases, while the $\mathrm{Au}-\mathrm{Pt} \mathrm{CN}$ increases. However, the overall $\mathrm{CN}$ of $\mathrm{Au}$ atoms remains below 9 , implying that they are located mainly on the surface. This is also observed from Figure 11 where, over a temperature range of 800 to $1000 \mathrm{~K}$, the $\mathrm{Au}$ atoms migrate from the edge sites toward mainly the $\{001\}$ terrace sites. The trajectory from the last $2 \mathrm{~ns}$ of the simulation shows that $\mathrm{Au}$ atoms become relatively mobile from ca. $900 \mathrm{~K}$. We observe that the $\mathrm{Au}$ atoms generally diffuse onto the top of the pristine $\{001\}$ terrace and, to a lesser extent, to the $\{111\}$ surface. The

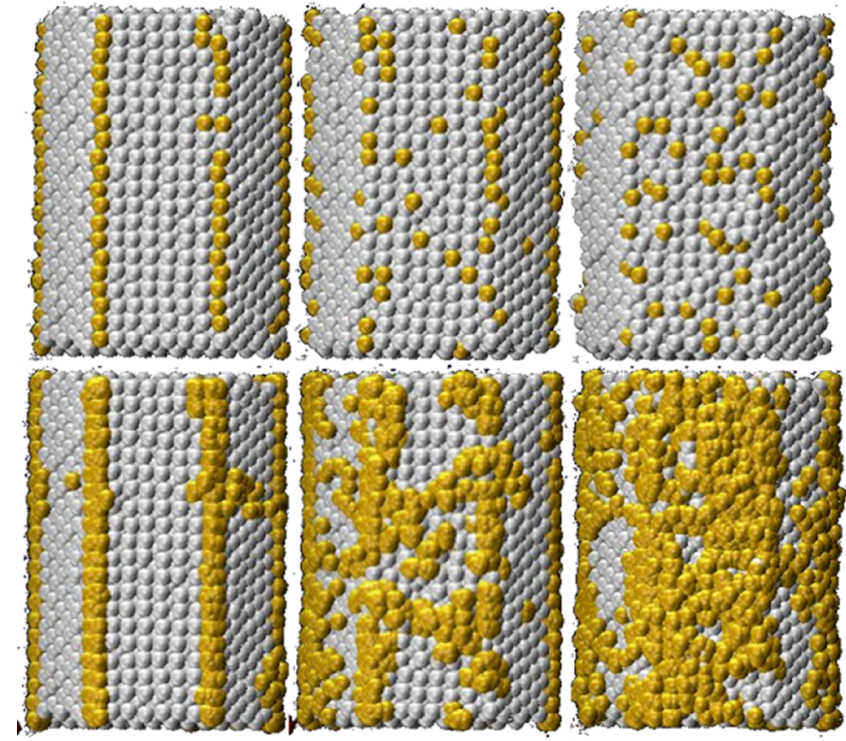

Figure 11. Final structure (top) and merged structures between 2 and $4 \mathrm{~ns}$ at $0.008 \mathrm{~ns}$ time steps (bottom) from a Au edge-modified Pt NW simulation. Left to right: 800,900 , and $1000 \mathrm{~K}$.

segregation behavior of $\mathrm{Ag}$ atoms in PtAg NWs appears to be similar to that in the PtAu system. We again observe that $\mathrm{Ag}$ atoms remain on the surface and migrate from edge sites mainly toward the $\{001\}$ facet (Table 2 and Figure 12). Ag atoms are relatively more mobile than $\mathrm{Au}$ at low temperatures (Figure 12).

In the PtPd modified system, we observe a decrease in the $\mathrm{Pd}-\mathrm{Pd} \mathrm{CN}$ and an increase in the Pd-Pt CN (Table 2 and Figure 13). A closer look at the $\mathrm{Pd}-\mathrm{Pd}$ radial pair distribution function plot (Figure S9a in the Supporting Information) shows how the nearest neighbor distribution decreases with temperature relative to the third nearest neighbor shell. The latter is consistent with the mixing behavior discussed in Section 3.3.1. This behavior implies that the formation of Pd$\mathrm{Pt}$ bonds is energetically favored over Pd-Pd bonds. Our analysis shows that the mobility of Pd mainly occurs in the core and, to some degree, onto the $\{001\}$ facet of the Pt NW, shown in Figure 13. We can rationalize this behavior based on the observed tendency of $\mathrm{Au}$ and $\mathrm{Ag}$ atoms to migrate to the surface compared to the subsurface migration of $\mathrm{Pd}$ atoms. The $\mathrm{Au}$ and $\mathrm{Ag}$ atoms can move away from the edge sites and diffuse over pristine $\{111\}$ and $\{001\}$ terraces, but this process might be limited in the Pd-modified NW. Overall, in agreement with Sankaranarayanan et al., ${ }^{35}$ both our constrained and $\mathrm{MD}$ simulations predict surface segregation of $\mathrm{Pt}$ in all studied PtPd systems. 


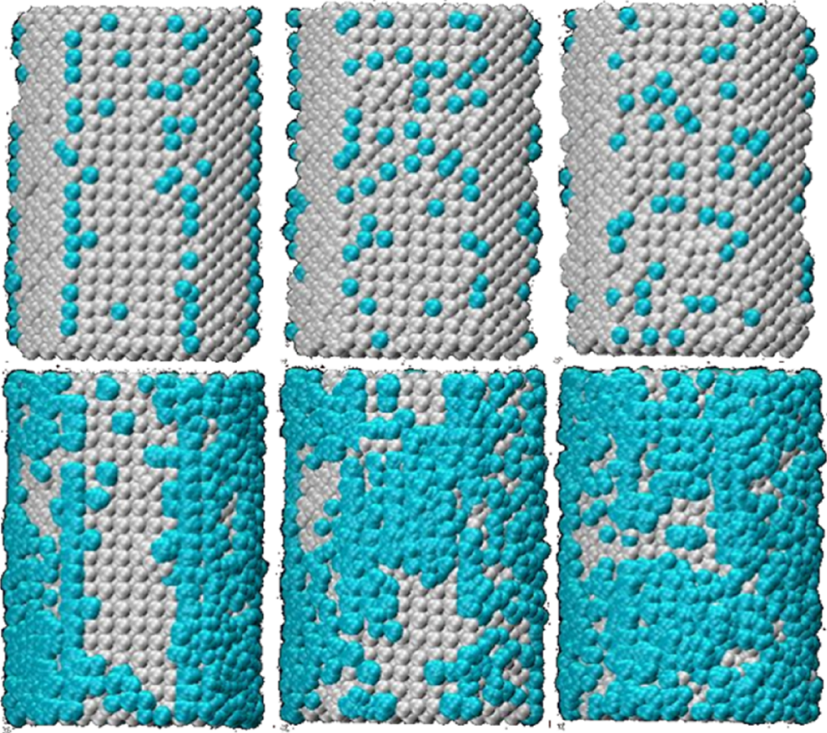

Figure 12. Final structure (top) and merged structures between 2 and 4 ns at 0.008 ns time steps (bottom) from a Ag edge-modified Pt NW simulation. Left to right: 800,900 , and $1000 \mathrm{~K}$.

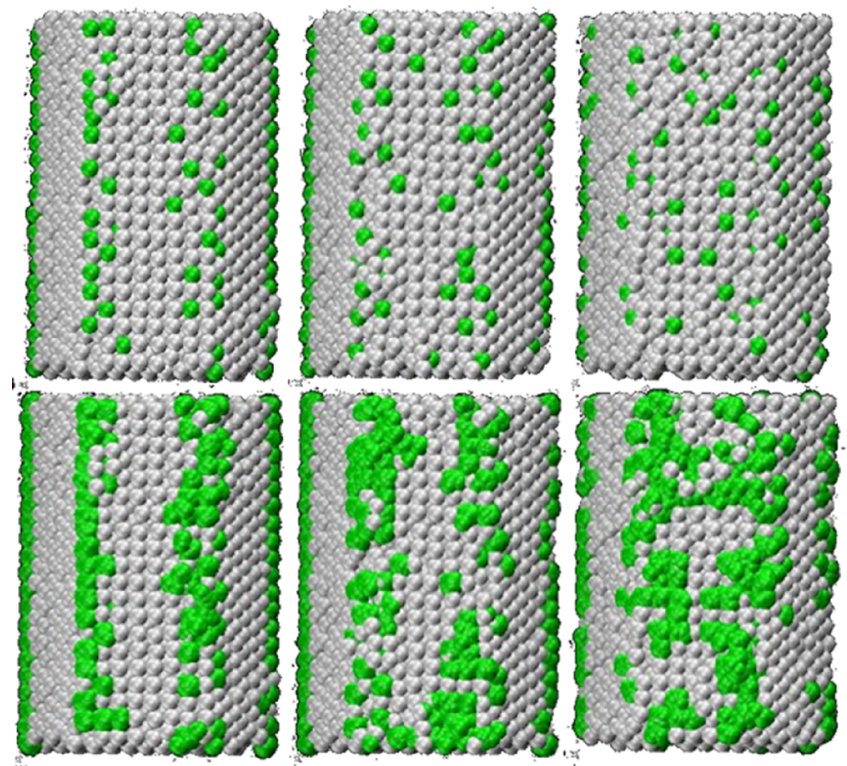

Figure 13. Final structure (top) and merged structures between 2 and $4 \mathrm{~ns}$ at $0.008 \mathrm{~ns}$ time steps (bottom) from a Pd edge-modified Pt NW simulation. Left to right: 800,900 , and $1000 \mathrm{~K}$.

\section{CONCLUSIONS}

We have investigated both the melting behavior and surface segregation of $\mathrm{Au}, \mathrm{Ag}$, and $\mathrm{Pd}$ on $\mathrm{ca} .4 \mathrm{~nm}$ diameter Pt NWs. This behavior is of significant relevance in heterogeneous catalysis, in particular for the electrochemical reduction of molecular oxygen under positive potentials. In addition to the slow kinetics of this reaction, the stability of the active Pt NPs is also an important factor to consider in the development of more attractive fuel cell catalysts. In this study, we have chosen the modifying atoms based on the need to improve the stability and activity of the Pt catalysts.

From our analyses, we observed that, as in NP materials, there is a strong dependency of the melting point temperature on the diameter of the NW. Our simulations show a decrease in the melting point temperatures for all modified $\mathrm{Pt}$ NWs compared to the unmodified NWs of equivalent size. The melting point temperature also decreases with increasing $\mathrm{Au}$, $\mathrm{Ag}$, and $\mathrm{Pd}$ surface composition in the following order: bare $\mathrm{Pt}$ NW > edge-modified PtM NW > shell-modified PtM NW. Despite this trend, due to poor agreement between SCpredicted melting points of bulk $\mathrm{Pt}$ and experiments, the degree of this effect remains qualitative.

As for trends in segregation behavior, we observe that, although both $\mathrm{Au}$ and $\mathrm{Ag}$ segregate to the surface, $\mathrm{Au}$ has the highest affinity. Unlike $\mathrm{Au}$ and Ag, however, Pd appears to prefer segregation toward the subsurface layers. In both our constrained energy minimization and relaxed MD simulations, we see that $\mathrm{Pd}$ atoms prefer homogeneous mixing with the core Pt atoms. While the MD simulations may not have been conducted for long enough data collection times to see the end of the Pd segregation behavior, we nevertheless feel confident that the final segregated structure contains a more mixed PtPd core, which is not predicted for the PtAu and PtAg systems.

In summary, while edge-decorated $\mathrm{Pt} \mathrm{NWs}$ or even NPs are desirable to improve the ORR activity, they may not be easily attained via thermal annealing in vacuum. We recommend that different reactive gas environments, such as $\mathrm{O}_{2}$ and $\mathrm{H}_{2}$, could be considered to direct the conversion of the $\mathrm{PtAu}$ or $\mathrm{PtAg}$ mixed-surface layer into a $\mathrm{Au}$ or $\mathrm{Ag}$ edge-decorated system with a pure Pt core and terraces. Given their different affinities for $\mathrm{Pt}$ and $\mathrm{M}$ atoms, $\mathrm{O}_{2}$ and $\mathrm{H}_{2}$ may be used to induce edgedecorated NWs. Finally, our simulations have also shown that at annealing temperatures below $1000 \mathrm{~K}$, the hexagonal NW morphology is preserved, while both $\mathrm{Au}$ and $\mathrm{Ag}$ atoms are relatively mobile within this temperature range. Our study suggests that $\mathrm{Au}$ and $\mathrm{Ag}$ remain the best candidate modifiers as they preferentially occupy surface sites, whereas Pd seems to be a less suitable candidate for future experiments.

\section{ASSOCIATED CONTENT}

\section{S Supporting Information}

The Supporting Information is available free of charge on the ACS Publications website at DOI: 10.1021/acs.jpcc.9b02730.

Energy and temperature convergence for a $4 \mathrm{~nm}$ diameter Pt NW with an axial length of $5.6 \mathrm{~nm}$, caloric curves for shell-modified Pt NWs, various projections of modified Pt NWs whose energy have been minimized through atomic swaps, pair distribution function plots for various edge-modified Pt NWs, Segregation energy of $M(M=\mathrm{Au}, \mathrm{Ag}$ and $\mathrm{Pd})$ in $\mathrm{Pt}$ NWs predicted by three empirical potential methods and DFT (PDF)

\section{AUTHOR INFORMATION}

\section{Corresponding Authors}

*E-mail: gmbtho002@myuct.ac.za (T.G.G.).

*E-mail: TerranovaU@cardiff.ac.uk. Phone: +44 (0)29 2087 0827 (U.T.).

*E-mail: deLeeuwN@cardiff.ac.uk. Phone: +44 (0)29 2087 0658 (N.H.d.L.).

ORCID $\odot$

Thobani G. Gambu: 0000-0002-6551-9220

Umberto Terranova: 0000-0001-7380-4737

Melissa A. Petersen: 0000-0002-2755-0323

Eric van Steen: 0000-0003-4659-8522

Nora H. de Leeuw: 0000-0002-8271-0545 


\section{Notes}

The authors declare no competing financial interest.

\section{ACKNOWLEDGMENTS}

We acknowledge the U.K. Engineering and Physical Research Council (grant nos. EP/K016288/1 and EP/K009567/2) and U.K. Economic and Social Research Council (grant no. ES/ N013867/1) as well as the National Research Foundation, South Africa, for funding. This research was undertaken using the Supercomputing Facilities at Cardiff University operated by ARCCA on behalf of CSF and Supercomputing Wales. This equipment is partly funded by the Welsh European Funding Office (WEFO) as well as by the University. The authors also acknowledge the Centre for High Performance Computing (CHPC), South Africa, for providing computational resources to this research project used to conduct additional calculations. T.G.G. is grateful to the Department of Science and Technology (DST) and the National Research Foundation (NRF) of South Africa, the Harry Crossley Foundation, and Johnson Matthey for doctoral funding. D.S.-C. is grateful to the Department of Science and Technology (DST) and the National Research Foundation (NRF) of South Africa for the provision of a Postdoctoral Fellowship for Early Career Researchers from the United Kingdom. All data created during this research is openly available from the Cardiff University's Research Portal at http://doi.org/10.17035/d.2019. 0077930441.

\section{REFERENCES}

(1) Gasteiger, H. A.; Baker, D. R.; Carter, R. N.; Gu, W.; Liu, Y.; Wagner, F. T.; Yu, P. T. Electrocatalysis and Catalyst Degradation Challenges in Proton Exchange Membrane Fuel Cells. In Hydrogen Energy; Stolten, D., Ed.; WILEY-VCH Verlag GmbH \& Co. KGaA: Weinheim, 2010; pp 3-16.

(2) Nørskov, J. K.; Rossmeisl, J.; Logadottir, A.; Lindqvist, L.; Kitchin, J. R.; Bligaard, T.; Jónsson, H. Origin of the Overpotential for Oxygen Reduction at a Fuel-Cell Cathode. J. Phys. Chem. B 2004, 108, 17886-17892.

(3) Nie, Y.; Li, L.; Wei, Z. Recent Advancements in Pt and Pt-Free Catalysts for Oxygen Reduction Reaction. Chem. Soc. Rev. 2015, 44, 2168-2201.

(4) Su, L.; Jia, W.; Li, C.-M.; Lei, Y. Mechanisms for Enhanced Performance of Platinum-Based Electrocatalysts in Proton Exchange Membrane Fuel Cells. ChemSusChem 2014, 7, 361-378.

(5) Liang, Y.-T.; Lin, S.-P.; Liu, C.-W.; Chung, S.-R.; Chen, T.-Y.; Wang, J.-H.; Wang, K.-W. The Performance and Stability of the Oxygen Reduction Reaction on $\mathrm{Pt}-\mathrm{M}(\mathrm{M}=\mathrm{Pd}, \mathrm{Ag}$ and $\mathrm{Au})$ Nanorods: An Experimental and Computational Study. Chem. Commun. 2015, 51, 6605-6608.

(6) Deng, S.; Kurttepeli, M.; Deheryan, S.; Cott, D. J.; Vereecken, P. M.; Martens, J. A.; Bals, S.; van Tendeloo, G.; Detavernier, C. Synthesis of a 3D Network of Pt Nanowires by Atomic Layer Deposition on a Carbonaceous Template. Nanoscale 2014, 6, 69396944.

(7) Zhou, H.; Zhou, W.; Adzic, R. R.; Wong, S. S. Enhanced Electrocatalytic Performance of One-Dimensional Metal Nanowires and Arrays Generated via an Ambient, Surfactantless Synthesis. J. Phys. Chem. C 2009, 113, 5460-5466.

(8) Koenigsmann, C.; Zhou, W. P.; Adzic, R. R.; Sutter, E.; Wong, S. S. Size-Dependent Enhancement of Electrocatalytic Performance in Relatively Defect-Free, Processed Ultrathin Platinum Nanowires. Nano Lett. 2010, 10, 2806-2811.

(9) Xia, B. Y.; Ng, W. T.; Wu, H. B.; Wang, X.; Lou, X. W. SelfSupported Interconnected Pt Nanoassemblies as Highly Stable Electrocatalysts for Low-Temperature Fuel Cells. Angew. Chem., Int. Ed. 2012, 51, 7213-7216.
(10) Liang, Y.-T.; Liu, C.-W.; Chen, H.-S.; Lin, T.-J.; Yang, C.-Y.; Chen, T.-L.; Lin, C.-H.; Tu, M.-C.; Wang, K.-W. Enhancement of Oxygen Reduction Reaction Performance of Pt Nanomaterials by 1Dimensional Structure and Au Alloying. RSC Adv. 2015, 5, 3920539208.

(11) Xia, Y.; Xiong, Y.; Lim, B.; Skrabalak, S. E. Shape-Controlled Synthesis of Metal Nanocrystals: Simple Chemistry Meets Complex Physics? Angew. Chem., Int. Ed. 2009, 48, 60-103.

(12) Meng, H.; Zhan, Y.; Zeng, D.; Zhang, X.; Zhang, G.; Jaouen, F. Factors Influencing the Growth of Pt Nanowires via Chemical SelfAssembly and Their Fuel Cell Performance. Small 2015, 11, 33773386.

(13) Sui, S.; Wang, X.; Zhou, X.; Su, Y.; Riffat, S.; Liu, C. A Comprehensive Review of $\mathrm{Pt}$ Electrocatalysts for the Oxygen Reduction Reaction: Nanostructure, Activity, Mechanism and Carbon Support in PEM Fuel Cells. J. Mater. Chem. A 2017, 5, 1808-1825.

(14) Bu, L.; Feng, Y.; Yao, J.; Guo, S.; Guo, J.; Huang, X. Facet and Dimensionality Control of Pt Nanostructures for Efficient Oxygen Reduction and Methanol Oxidation Electrocatalysts. Nano Res. 2016, 9, 2811-2821.

(15) Jiang, K.; Zhao, D.; Guo, S.; Zhang, X.; Zhu, X.; Guo, J.; Lu, G.; Huang, X. Efficient Oxygen Reduction Catalysis by Subnanometer Pt Alloy Nanowires. Sci. Adv. 2017, 3, No. e1601705.

(16) Huang, H.; Li, K.; Chen, Z.; Luo, L.; Gu, Y.; Zhang, D.; Ma, C.; Si, R.; Yang, J.; Peng, Z.; et al. Achieving Remarkable Activity and Durability toward Oxygen Reduction Reaction Based on Ultrathin Rh-Doped Pt Nanowires. J. Am. Chem. Soc. 2017, 139, 8152-8159.

(17) Markovic, N. Kinetics of Oxygen Reduction on Pt(hkl) Electrodes: Implications for the Crystallite Size Effect with Supported Pt Electrocatalysts. J. Electrochem. Soc. 1997, 144, 1591.

(18) Maciá, M. D.; Campiña, J. M.; Herrero, E.; Feliu, J. M. On the Kinetics of Oxygen Reduction on Platinum Stepped Surfaces in Acidic Media. J. Electroanal. Chem. 2004, 564, 141-150.

(19) Kuzume, A.; Herrero, E.; Feliu, J. M. Oxygen Reduction on Stepped Platinum Surfaces in Acidic Media. J. Electroanal. Chem. 2007, 599, 333-343.

(20) Greeley, J.; Rossmeisl, J.; Hellmann, A.; Norskov, J. K. Theoretical Trends in Particle Size Effects for the Oxygen Reduction Reaction. Zeitschrift für Physikalische Chemie 2007, 221, 1209-1220.

(21) Duan, Z.; Wang, G. A First Principles Study of Oxygen Reduction Reaction on a Pt(111) Surface Modified by a Subsurface Transition Metal M $(\mathrm{M}=\mathrm{Ni}$, Co, or Fe). Phys. Chem. Chem. Phys. 2011, 13, 20178-20187.

(22) Duan, Z.; Wang, G. Comparison of Reaction Energetics for Oxygen Reduction Reactions on $\mathrm{Pt}(100), \mathrm{Pt}(111), \mathrm{Pt} / \mathrm{Ni}(100)$, and $\mathrm{Pt} / \mathrm{Ni}(111)$ Surfaces: A First-Principles Study. J. Phys. Chem. C 2013, $117,6284-6292$.

(23) Li, K.; Li, Y.; Wang, Y.; He, F.; Jiao, M.; Tang, H.; Wu, Z. The Oxygen Reduction Reaction on $\mathrm{Pt}(111)$ and $\mathrm{Pt}(100)$ Surfaces Substituted by Subsurface Cu: A Theoretical Perspective. J. Mater. Chem. A 2015, 3, 11444-11452.

(24) Mayrhofer, K. J. J.; Blizanac, B. B.; Arenz, M.; Stamenkovic, V. R.; Ross, P. N.; Markovic, N. M. The Impact of Geometric and Surface Electronic Properties of Pt-Catalysts on the Particle Size Effect in Electrocatalysis. J. Phys. Chem. B 2005, 109, 14433-14440.

(25) Chen, C.; Kang, Y.; Huo, Z.; Zhu, Z.; Huang, W.; Xin, H. L.; Snyder, J. D.; Li, D.; Herron, J. A.; Mavrikakis, M.; et al. Highly Crystalline Multimetallic Nanoframes with Three-Dimensional Electrocatalytic Surfaces. Science 2014, 343, 1339-1343.

(26) Ou, L. The Origin of Enhanced Electrocatalytic Activity of Pt$\mathrm{M}(\mathrm{M}=\mathrm{Fe}, \mathrm{Co}, \mathrm{Ni}, \mathrm{Cu}$, and W) Alloys in PEM Fuel Cell Cathodes: A DFT Computational Study. Comput. Theor. Chem. 2014, 1048, 6976.

(27) Tritsaris, G. A.; Greeley, J.; Rossmeisl, J.; Nørskov, J. K. Atomic-Scale Modeling of Particle Size Effects for the Oxygen Reduction Reaction on Pt. Catal. Lett. 2011, 141, 909-913.

(28) Gambu, T. G.; Petersen, M. A.; van Steen, E. Probing the Edge Effect on the ORR Activity Using Platinum Nanorods: A DFT Study. Catal. Today 2018, 312, 126-131. 
(29) Komanicky, V.; Menzel, A.; You, H. Investigation of Oxygen Reduction Reaction Kinetics at (111)-(100) Nanofaceted Platinum Surfaces in Acidic Media. J. Phys. Chem. B 2005, 109, 23550-23557.

(30) Komanicky, V.; Iddir, H.; Chang, K.-C.; Menzel, A.; Karapetrov, G.; Hennessy, D.; Zapol, P.; You, H. Shape-Dependent Activity of Platinum Array Catalyst. J. Am. Chem. Soc. 2009, 131, 5732-5733.

(31) Wen, Y. N.; Zhang, J. M. Surface Energy Calculation of the Bcc Metals by Using the MAEAM. Comput. Mater. Sci. 2008, 42, 281285.

(32) Barmparis, G. D.; Lodziana, Z.; Lopez, N.; Remediakis, I. N. Nanoparticle Shapes by Using Wulff Constructions and FirstPrinciples Calculations. Beilstein J. Nanotechnol. 2015, 6, 361-368.

(33) Davey, W. P. Precision Measurements of the Lattice Constants of Twelve Common Metals. Phys. Rev. 1925, 25, 753-761.

(34) Sachtler, W. M. H.; van Santen, R. A. Surface Composition of Binary Alloys. Appl. Surf. Sci. 1979, 3, 121-144.

(35) Sankaranarayanan, S. K. R. S.; Bhethanabotla, V. R.; Joseph, B. Molecular Dynamics Simulation Study of the Melting of Pd-Pt Nanoclusters. Phys. Rev. B 2005, 71, 195415.

(36) Sankaranarayanan, S. K. R. S.; Bhethanabotla, V. R.; Joseph, B. Molecular Dynamics Simulations of the Structural and Dynamic Properties of Graphite-Supported Bimetallic Transition Metal Clusters. Phys. Rev. B 2005, 72, 195405.

(37) Kart, S. Ö.; Erbay, A.; Kılıç, H.; Cagin, T.; Tomak, M. Molecular Dynamics Study of Cu-Pd Ordered Alloys. J. Achiev. Mater. Manuf. Eng. 2008, 31, 41-46.

(38) Yang, Z.; Yang, X.; Xu, Z. Molecular Dynamics Simulation of the Melting Behavior of $\mathrm{Pt}-\mathrm{Au}$ Nanoparticles with Core-Shell Structure. J. Phys. Chem. C 2008, 112, 4937-4947.

(39) Qiao, Z.; Feng, H.; Zhou, J. Molecular Dynamics Simulations on the Melting of Gold Nanoparticles. Phase Transitions 2014, 87, 59-70.

(40) Yaghoubi, H. Melting Properties and Structural Evolution of (Ag x-Pd 1x ) 256 Bimetallic Nanoclusters Supported on SWCNT: A Molecular Dynamics Simulation. J. Mol. Liq. 2017, 230, 305-314.

(41) van der Walt, C.; Terblans, J. J.; Swart, H. C. A Study of Diffusion, Atom Migration and Segregation in $\mathrm{Cu}$ and $\mathrm{Ag}$ Alloy Bulkand Nanocrystals. AIP Adv. 2017, 7, No. 055102.

(42) Deng, L.; Hu, W.; Deng, H.; Xiao, S. Surface Segregation and Structural Features of Bimetallic Au-Pt Nanoparticles. J. Phys. Chem. C 2010, 114, 11026-11032.

(43) Cheng, D.; Hou, M. Structures, Thermal Stability, and Melting Behaviors of Free-Standing Pentagonal Multi-Shell Pd-Pt Nanowires. Eur. Phys. J. B 2010, 74, 379-390.

(44) De Clercq, A.; Giorgio, S.; Mottet, C. Pd Surface and Pt Subsurface Segregation in Pt1-CPdc Nanoalloys. J. Phys.: Condens. Matter 2016, 28, No. 064006.

(45) Watson, D. J.; Attard, G. A. Surface Segregation and Reconstructive Behaviour of the (100) and (110) surfaces of platinum-palladium bulk Alloy Single crystals: A Voltammetric and LEED/AES Study. Surf. Sci. 2002, 515, 87-93.

(46) Liu, H.; An, W.; Li, Y.; Frenkel, A. I.; Sasaki, K.; Koenigsmann, C.; Su, D.; Anderson, R. M.; Crooks, R. M.; Adzic, R. R.; et al. In Situ Probing of the Active Site Geometry of Ultrathin Nanowires for the Oxygen Reduction Reaction. J. Am. Chem. Soc. 2015, 137, 1259712609 .

(47) Ruban, A. V.; Skriver, H. L.; Nørskov, J. K. Surface Segregation Energies in Transition-Metal Alloys. Phys. Rev. B 1999, 59, 15990.

(48) Tripkovic, V.; Hansen, H. A.; Rossmeisl, J.; Vegge, T. First Principles Investigation of the Activity of Thin Film Pt, Pd and $\mathrm{Au}$ Surface Alloys for Oxygen Reduction. Phys. Chem. Chem. Phys. 2015, 17, 11647-11657.

(49) Zhang, J.; Vukmirovic, M. B.; Sasaki, K.; Nilekar, A. U.; Mavrikakis, M.; Adzic, R. R. Mixed-Metal Pt Monolayer Electrocatalysts for Enhanced Oxygen Reduction Kinetics. J. Am. Chem. Soc. 2005, 127, 12480-12481.

(50) Smith, W.; Foreste, T. R.; Todorov, I. T. The DL_POLY Classic

User Manual; Daresbury Laboratory: United Kingdom, 2012.
(51) Evans, D. J.; Morriss, O. P. Non-Newtonian Molecular Dynamics. Comput. Phys. Rep. 1984, 1, 297-343.

(52) Sutton, A. P.; Chen, J. Long-Range Finnis-Sinclair Potentials. Philos. Mag. Lett. 1990, 61, 139-146.

(53) Kimura, Y.; Qi, Y.; Çağın, T. C.; Goddard, III, W. A. The Quantum Sutton-Chen Many-Body Potential for Properties of fcc Metals. Caltech ASCI Technical Report 003; California Institute of Technology: Pasadena, CA, 1998.

(54) van der Walt, C.; Terblans, J. J.; Swart, H. C. Molecular Dynamics Study of the Temperature Dependence and Surface Orientation Dependence of the Calculated Vacancy Formation Energies of $\mathrm{Al}, \mathrm{Ni}, \mathrm{Cu}, \mathrm{Pd}, \mathrm{Ag}$, and Pt. Comput. Mater. Sci. 2014, $83,70-77$.

(55) Steinhardt, P. J.; Nelson, D. R.; Ronchetti, M. BondOrientational Order in Liquids and Glasses. Phys. Rev. B 1983, 28, 784-805.

(56) Wang, Y.; Teitel, S.; Dellago, C. Melting of Icosahedral Gold Nanoclusters from Molecular Dynamics Simulations. J. Chem. Phys. 2005, 122, 214722.

(57) Wen, Y. H.; Zhang, Y.; Zheng, J. C.; Zhu, Z. Z.; Sun, S. G. Orientation-Dependent Structural Transition and Melting of Au Nanowires. J. Phys. Chem. C 2009, 113, 20611-20617.

(58) Li, M.; Cheng, D. Molecular Dynamics Simulation of the Melting Behavior of Crown-Jewel Structured Au-Pd Nanoalloys. J. Phys. Chem. C 2013, 117, 18746-18751.

(59) Tamura, Y.; Arai, N. Molecular Dynamics Simulation of the Melting Processes of Core-Shell and Pure Nanoparticles. Mol. Simul. 2015, 41, 905-912.

(60) Liang, T.; Zhou, D.; Wu, Z.; Shi, P. Size-Dependent Melting Modes and Behaviors of Ag Nanoparticles: A Molecular Dynamics Study. Nanotechnology 2017, 28, 485704.

(61) Guisbiers, G.; Abudukelimu, G.; Hourlier, D. Size-Dependent Catalytic and Melting Properties of Platinum-Palladium Nanoparticles. Nanoscale Res. Lett. 2011, 6, 396.

(62) Ahmed, A.; Elvati, P.; Violi, A. Size-and Phase-Dependent Structure of Copper(Ii) Oxide Nanoparticles. RSC Adv. 2015, 5, 35033-35041.

(63) Sushko, G. B.; Verkhovtsev, A. V.; Kexel, C.; Korol, A. V.; Schramm, S.; Solov'yov, A. V. Reconciling Simulated Melting and Ground-State Properties of Metals with a Modified Embedded-Atom Method Potential. J. Phys.: Condens. Matter 2016, 28, 145201.

(64) Todd, B. D.; Lynden-Bell, R. M. Surface and Bulk Properties of Metals Modelled with Sutton-Chen Potentials. Surf. Sci. 1993, 281, 191-206. 